\title{
Virology of SARS-CoV-2 and management of nCOVID-19 utilizing immunomodulation properties of human mesenchymal stem cells - a literature review
}

\author{
Kunj Sachdeva $^{1 \# \wedge}$, Anil Kumar ${ }^{2,3 \#}$, Sujata Mohanty ${ }^{1 \wedge}$ \\ ${ }^{1}$ Stem Cell Facility (DBT-Centre of Excellence for Stem Cell Research), All India Institute of Medical Sciences, New Delhi, India; ${ }^{2}$ Amity Institute of \\ Biotechnology, Amity University Haryana, Amity Education Valley, Gurugram, India; ${ }^{3}$ School of Engineering and Sciences, GD Goenka University, \\ Gurugram, Haryana, India \\ Contributions: (I) Conception and design: S Mohanty; (II) Administrative support: Centre of Excellence for Stem Cell Research, All India Institute \\ of Medical Sciences, New Delhi, Ansari Nagar, New Delhi, Delhi 110029; Amity Institute of Biotechnology, Amity University, Gurgaon; School of \\ Engineering and Sciences, GD Goenka University, Gurugram, Haryana, India; (III) Provision of study materials or patients: None; (IV) Collection \\ and assembly of data: K Sachdeav, A Kumar; (V) Data analysis and interpretation: All authors; (VI) Manuscript writing: All authors; (VII) Final \\ approval of manuscript: All authors. \\ "These authors contributed equally to this work. \\ Correspondence to: Sujata Mohanty, PhD. Stem Cell Facility, DBT-Centre of Excellence for Stem Cell Research, 1st Floor, ORBO Complex All India \\ Institute of Medical Sciences, Ansari Nagar, New Delhi, India. Email: drmohantysujata@gmail.com.
}

\begin{abstract}
Objective: The objective of this review article is to outline the pathology, virology and mechanism of severe acute respiratory syndrome-corona virus-2 (SARS-CoV-2) and to study the regenerative role of mesenchymal stem cells (MSCs) to tackle the lung damage caused by SARS-CoV-2.

Background: The MSCs possess trophic potentialities which enable them to find out the sites of injury or inflammation and because of their pleiotropic and pericytic nature, these cells are capable of differentiating into different cell types. The MSCs can be derived from a variety of tissue sources be it adult or embryonic origin. The one major characteristic of MSCs is that they are immunologically naïve in terms of expression of MHC Class II. This very low or no expression of MHC class II makes them useful in clinical settings where they can be used in allogenic transplant cases. This allogenic transplant possibilities of these MSCs makes them one of the most researched stem cells and investigated for cell-based therapies. Though these MSCs are in clinical settings for long the one even more important characteristic which makes them even more in demand is their immunomodulatory properties which have been used in various cases to mitigate the effect of overstimulation of the immune system. In recent times after the pandemic of the novel corona virus disease 2019 (nCOVID-19) generated by SARS-CoV-2, the effect of various MSCs isolated from various tissue sources are being utilized to curb the overstimulation of immune response, so that the immune system can be brought under some regulation to ultimately reduce the effect of inflammation.
\end{abstract}

Methods: In this review article, we have reviewed the existing literature, data and ongoing clinical trials by using keywords like novel coronavirus, COVID-19, SARS-CoV-2, MERS-CoV, acute respiratory distress syndrome, mesenchymal stem cells, immunomodulation properties of stem cells, regenerative properties of stem cells, cell therapy, clinical trials of stem cells, clinical trials of COVID-19 and stem cells till 20th August 2020 using database named PubMed, NCBI, Google Scholar, Scopus, Research Gate and Clinicaltrials.gov. Conclusions: Thus, concluding the therapeutic potential of MSCs in managing and treating COVID-19.

Keywords: Corona virus disease 2019 (COVID-19); coronavirus; mesenchymal stem cell (MSC); immunomodulation; lung diseases

^ ORCID: Kunj Sachdeva, 0000-0002-6002-0594; Anil Kumar, 0000-0003-0327-9118; Sujata Mohanty, 0000-0002-0047-4914. 
Received: 30 August 2020; Accepted: 18 September 2021; Published: 10 November 2021.

doi: $10.21037 /$ sci-2020-040

View this article at: https://dx.doi.org/10.21037/sci-2020-040

\section{Introduction}

Stem cells are cells in nut cell can be defined as obligatory, asynchronous replicators. These cells are mesengenic cells, meaning they give rise to the tissue such as muscle, cartilage, bone, tendon, dermis, marrow stroma, connective tissues and fat $(1,2)$. Human mesenchymal stem cells (hMSCs) are characterized by a set of markers (CD29, CD44, CD73, CD90, CD105) and lack the expression of CD14, CD34, CD45 and human leukocyte antigen (HLA) as proposed in 2006 by the International Society for Cellular Therapy (3). These cells reside in the pockets in almost all organs of an adult individual and protect the body from the general wear and tear process. Different pockets/niches in human body where MSCs reside are the heart (4), peripheral blood (5), cord blood (6), muscle (7), adipose tissue (8), lung (9), trabecular bone (10), intestine (11), kidney (12), liver (13), pancreas (14), synovium (15), skin (16), hair follicle $(17,18)$, and even in the brain (19). These niches are specialized cell pockets that provide a necessary microenvironment for their survival and support.

Depending upon the origin of the tissue these stem cells are classified as adult stem cells (ASCs) or embryonic stem cells (ESCs). Differentiated adult stem cells which are induced to behave as pluripotent are called as induced pluripotent stem cells (iPSC) (20). Mesenchymal stem cells (MSCs) which are generally used in clinical settings are of adult origin. Though MSCs can be expanded from the embryonic stem cells the potential of undifferentiated embryonic stem cells to form teratoma (cancer of all the three germ layers) in nude mice generally limits their therapeutic potential (21). hMSCs in immune modulation have been reported in autoimmune diseases. Like inflammatory airway disorders (22), graft versus host disease (GVHD) (23) and in a disease model of autoimmune diseases such as systemic lupus erythematosus (SLE) (24) multiple sclerosis (25). In the recent outbreak if novel corona virus disease 2019 (nCOVID-19) pandemic hMSCs are being envisioned as a tool to modulate the immune response of the affected population and reports/reviews have started coming out wherein hMSCs are being used in the management of the nCOVID-19 (26-30).

A graphical abstract is available in the supplementary material (Figure S1). We present the following article in accordance with the narrative review reporting checklist (available at https://dx.doi.org/10.21037/sci-2020-040).

\section{Virology of severe acute respiratory syndrome- corona virus-2 (SARS-CoV-2)}

The novel coronavirus disease 2019 (nCOVID-19) pandemic hits the present century so hard that the technology and economy freeze from its side effects (31). The coronavirus responsible for a nCOVID-19 pandemic is SARS-CoV-2 and is a new strain of coronavirus that hasn't been recognized in humans up until December 2019 (27). The Coronavirus has already caused the disease among humans however with different strains such as severe acute respiratory syndrome (SARS-CoV) and middle east respiratory syndrome (MERS-CoV) (27). Coronavirus enveloped with a positive-sense, single-stranded RNA genome (with nucleocapsid) ranged from 26-32 kb (32), which is the largest discovered RNA virus (27) in a genome with length structure and identity sequence is $79.6 \%$ identical to SARS-CoV (33). From the four $(\alpha, \beta, \gamma, \delta)$ coronavirus genera, human coronavirus ( $\mathrm{HCoVs}$ ) is spotted in $\alpha$ coronavirus genera (NL63 and $\mathrm{HCoV}-229 \mathrm{E}$ ) and $\beta$ coronavirus genera (SARS-CoV, HCoV-HKU1, MERS$\mathrm{CoV}$ and $\mathrm{HCoV}-\mathrm{OC} 43)$ (34). The $\beta$ coronavirus genera indicate $88 \%$ identical with the sequence of two-bat derived severe acute respiratory syndrome (SARS)-like coronavirus, bat-SL-CoVZXC21 and bat-SL-CoVZC45 and nearly $50 \%$ identical to the sequence of MERS-CoV (34). Thus, the novel $\beta-\mathrm{CoV}$ was termed as "SARS-CoV-2" by the International Virus Classification Commission (35).

SARS-CoV-2 genome contains ten open reading frames $(\mathrm{ORF})$. The first open reading frame $(\mathrm{ORF} 1 \mathrm{a} / \mathrm{b})$ are about $2 / 3^{\text {rd }}$ of viral RNA, and are transferred into larger two polyproteins. In SARS-CoV and MERS-CoV, pp1a and pp1ab (two polyproteins) are processed into sixteen nonstructured proteins (nsp1 - nsp16), which will further form the viral replicase transcriptase complex (35). Such nonstructured proteins readjust Rough Endoplasmic Reticulum (RER) originating membranes towards double-membrane vesicles where transcription and viral replication occurs (36). The another open reading frames of SARS-CoV-2 on the 
$1 / 3^{\text {rd }}$ of the genome encodes for four structural proteins named nucleocapsid $(\mathrm{N})$, spike $(\mathrm{S})$, envelope and membrane (M) protein as well as numerous accessory proteins with undefined role and don't have any role in viral replication (35).

\section{Pathogenesis of SARS-CoV-2}

SARS-CoV-2 affected patients come up with clinical manifestations including shortness of breath, dry cough, fever, fatigue, myalgia, evidence of pneumonia based on radiographic evidence, and decreased leukocyte counts (37), which are very much similar to SARS-CoV and MERS$\mathrm{CoV}$ infections (38). Though the precious pathogenesis of SARS-CoV-2 is still poorly understood, but the overall mechanism of SARS-CoV and MERS-CoV open ups the information source on the pathogenesis of SARS-CoV-2 infection $(27,31)$.

\section{Interaction of virus protein with the human surface receptors}

The $\mathrm{S}$ protein on coronavirus surface has been reported as a ticket to admission the virus into host cells (39) by recognizing the Angiotensin I converting enzyme 2 (ACE2) receptor by its spike protein $(33,40,41)$. The enveloped spike glycol protein binds to its cellular receptor in the following manner as Angiotensin I converting enzyme 2 for SARS-CoV-2 (42) and SARS-CoV (43), CD209L (C-type lectin) called L-SIGN for SARS-CoV (44), DPP4 for MERS-CoV (45). Regrettably, the ACE2 receptor is distributed widely on the surface of human cells, specifically the alveolar type 2 of the lungs $(46,47)$. The ACE2 receptor are also presents abundantly on heart, liver, kidney and digestive organs, altogether the smooth muscle cells and endothelial cells in organs express ACE2, thus the virus can enter speedily within the body through blood circulation (31). Thus, all the organs and tissue expressing Angiotensin I converting enzyme 2 could be involved in the battlefield of nCOVID-19 and explains why the patients suffering from respiratory distress syndrome also suffer from multiple organ dysfunction (MOD) including acute kidney shock, acute myocardial injury, shock and arrhythmia (28,37). Parallelly, a study done by Hoffmann et al. (48) demonstrated that cellular serine protease TMRRSS2 is needed to permit coronavirus entry into the host cells and it is plausible that human cells like capillary endothelium and alveolar type 2 (46) contains well distributed ACE2 receptor all over the surface and those alveolar type 2 cells largely express TMPRSS2 (48-50).

Back the coronavirus entry mechanism which is initiated by direct membrane fusion between the plasma membrane and the virus (50,51). Belouzard et al. (52) demonstrated a critical proteolytic cleavage incident occurred at S2' position of $\mathrm{S}$ protein in SARS-CoV medicated the membrane fusion and viral infectivity. In addition to membrane fusion, the clathrin-independent and dependent endocytosis fascinate SARS-CoV entry too $(53,54)$. Following the virus entrance within the cells, the viral RNA genome let out within the cytoplasm and decode into structural protein and tow polyprotein, afterwards the genome of virus initiates duplication and replication (34). The afresh designed enveloped glycoprotein are intersected within the membrane of Golgi or ER (endoplasmic reticulum), and the nucleocapsid is molded by the blend of genomic RNA and nucleocapsid protein. Afterwards, the particles of virus shoot-up at the Endoplasmic reticulum-Golgi intermediate compartment (ERGIC) (35). At last, the virus particles contained by vesicles start fusing with the plasma membrane to discharge the virus (39).

\section{Presentation of coronavirus antigen}

After the virus enters into the cell, an antigen is offered to the antigen presentation cells (APC), this one has a fundamental role in the anti-viral immunity of the body. Antigen peptides being accessible by human leukocyte antigen (HLA) or major histocompatibility complex (MHC) recognized by virus-specific cytotoxic $\mathrm{T}$ lymphocytes (CTLs) in humans (35). Therefore, knowledge of antigen presentation in SARS-CoV-2 is must for the better understanding the nCOVID-19 pathogenesis. Although, SARS-CoV antigen presentation mainly depends on MHC I (55) molecule but MHC II also contributes to its presentation. Earlier reports suggested the SARS$\mathrm{CoV}$ susceptibility correlates with HLA polymorphism such as HLA-B ${ }^{*} 4601$, HLA-B ${ }^{*} 0703$, HLA-DR B1*1202, HLA-B*4601, HLA-B*0703 (56) and HLA-CW*0801 (57), however the HLA-DR0301, HLA-A*0201 and HLACW1502 alleles, on the other hand, provides protection from SARS infection (58). During MERS-CoV infection susceptibility to infection is associated with Major Histocompatibility Complex II (MHC II) like HLADRB1*11:01 and HLA-DQB1*02:0 (59). Likewise, gene polymorphisms of MBL (mannose-binding lectin) associated with antigen presentation are correlated to higher SARS-CoV infection risk (60). Such pieces of information 
would deliver high beneficial evidences for the mechanism and treatment of nCOVID-19.

\section{Evasion of immune surveillance}

SARS-CoV and MERS-CoV sustain in host cells by using multiple approaches by avoiding immune response. An evolutionary conserved microbial structure called pathogen-associated molecular patterns (PAMPs) can be recognized by pattern recognition receptors (PRRs) (35). However, SARS-CoV and MERS-CoV can persuade double-membrane vesicles production then replicates in these vesicles that lack PRRs, thus avoiding the host detection of their dsRNA (61). IFN- $\beta$ (IFN-I) and IFN- $\alpha$ provide shielding effects on SARS-CoV and MERS$\mathrm{CoV}$ but in an infected mouse, IFN-I pathway is inhibited $(62,63)$. MERS-CoV, accessory protein 4 a may chunk the induction of interferon at the level of MDA5 activation through interaction with double-stranded RNA (64). In addition to membrane proteins of MERS-CoV and ORF5, ORF4a, ORF4b inhibit nuclear transport of interferon regulatory factor 3 (IRF3) and stimulation of interferon $\beta$ (IFN $\beta$ ) promoter (65). Coronavirus also affects the antigen presentation like gene expression related antigen presentation is down-regulated after MERS-CoV infection (66). Thus, smashing the immune evasion of SARS-CoV-2 is very crucial for the effective treatment against the virus.

\section{Cytokine storm}

Interestingly, B and T lymphocytes (Immune cells), bone marrow, thymus, spleen and macrophages are negative for ACE2 $(28,46)$. These detections suggest that the patients suffering from Coronavirus may be treated with immunological therapy, however when the patient's own over activated immune system kills the virus, it generates inflammatory factors in larger number subsequently lead to cytokine storm $(28,37)$. The deadly uncontrollable inflammatory response results in releasing of a terrible amount of pro-inflammatory cytokines (IFN- $\alpha$, IFN- $\gamma$, TNF- $\alpha$, TGF- $\beta$, IL-33, IL-18, IL-12, IL-6, IL-1 $\beta$, etc.) and Chemokines (CXCL10, CXCL9, CXCL8, CCL5, CCL3, CCL2, etc.) in the lungs through immune effector cells in SARS-CoV infection (28,37,67-69). Similarly, infection MERS-CoV showed higher levels of IL-6, IFN- $\alpha$, IL-6, CCL5, CXCL8, CXCL10 in diseased patients (70). Therefore, sidestepping the cytokine storm maybe crucial for treating nCOVID-19 diseased patients as the cytokine storm stimulate attack by the body's own immune system that further cause acute respiratory distress syndrome, cardiac arrest, dysfunction of the air exchange and MOD, which finally leads to death in nCOVID-19 infection just like in SARS-CoV and MERS-CoV infection $(28,37,40)$.

\section{Response of humoral and cellular immunity}

Cellular and humoral immunity in the body stimulate by the antigen presentation subsequently, which is driven through a virus specific $T$ cells and $B$ cells. Likewise, to other acute viral infection, the $\mathrm{AB}$ (antibody) profiles against SARS$\mathrm{CoV}$ produces the typical IgM and IgG pattern (35). The SARS specific IgG antibody may last for a longer time as compared to IgG antibody which usually disappears by the end of 12 weeks, thus it may be concluded that IgG antibody plays a protective role against the virus (71). Many publications on such areas are more concerned about the cellular immunity comparing to humoral response against coronavirus study (35). The study by (72) demonstrated that number of CD8+ and CD4+ T cells in the SARS-CoV-2 diseased patient peripheral blood is reduced significantly, while its status activated, as evinced by a higher proportion of CD38 (CD8, 39.4\%) HLA-DR (CD4, 3.47\%) (73). Also, the acute phase response in SARS-CoV patients is indicated with decreased CD4+ and CD8+ T cells. Even, in case of no antigen, CD4+ and CD8+ memory $\mathrm{T}$ cells can stay for up to almost 4 years in a part of SARS-CoV recovered individuals and can perform proliferation of $\mathrm{T}$ cells, production of IFN- $\gamma$ and DTH response (71). Six years after SARS-CoV infection, specific T-cells memory responses to the SARSCoV S peptide library could still be identified in 14 of 23 recovered SARS-CoV patients $(35,74)$. The specified CD8+ $\mathrm{T}$ cells turned up showing akin event on MERS-CoV clearance in mice (75). This piece of information may prove valuable for working on the therapy aspects of nCOVID-19.

\section{Management of nCOVID-19}

Approximately 90 vaccines are being developed to fight against nCOVID-19 by research corporates and universities around the globe (76,77). Scientists are trialing and validating several technologies, some of which have not been used in licensed treatment/vaccination before. A study (76) grouped a few vaccines like Virus vaccines, Nucleic-acid vaccines, Protein-based vaccines, and Viralvector vaccines, that have already started injecting into volunteers for safety trials and some for-animal studies (76). 
Mesenchymal SCs transplantation can improve the outcomes in patients suffering from nCOVID-19 related symptoms. Parallelly, the Italian College of Anesthesia, Analgesia, Resuscitation, and Intensive care have issued certain guidelines to treat nCOVID-19 diseased cases (47), by indicating the declaration of the key potentiality of stem cells to relief the nCOVID-19 patients quickly (47).

Immunological therapy may be considered as one of the potential treatment but the immunomodulatory capacity can't stand strong alone in case of only or two immune factors will be considered because the virus has the ability to stimulate cytokine storm in the lungs itself, which further lead to acute respiratory distress syndrome (ARDS), multiorgan failure, cardiac arrest, and other infection which results into deadly outcomes $(28,37)$. Therefore, avoiding/ evading cytokine storm is better while treating nCOVID-19 infected population which also mean immunological therapies may not be sufficient to fight against the deadly virus (28,31). However, 'Master Cells' or stem cells like MSCs have the intrinsic powerful immunomodulatory ability and carry the advantage for attenuating cytokine Storm and thereby beneficial as a therapy to treat nCOVID-19 infected patients $(27,28,31)$.

Cell-therapies are leading the biomedical research ranging from tissue engineering to regenerative medicine and incorporated in curing a number of diseases including cardiovascular (78-80), pulmonary (81-84), renal (85-87) etc. On the other hand, despite numerous literatures stating the immunomodulatory or regenerative effect of stem cellbased therapies, federal trade commission (FTC) issued legal lawsuit against stem cell-based therapy in clinical practices (88). Throughout the controversial background of stem cell-based therapy, Food and Drug Administration (FDA) have considered multiple clinical trials of stem cell therapy and issued new guidance and clearance before practicing the therapy on the roadway of the clinic (89-95). The deadly virus infection and spread has assembled researchers and clinicians from different life sciences branches to find a treatment or the solution towards the ongoing worst pandemic of this century. International Society for Stem Cell Research (ISSCR) has recently announced that presently there is no approved stem cellbased therapy for treating and preventing of coronavirus infection (27). However, just as the other multiple treatment strategies are into the pipeline, MSCs have been introduced as a potential therapeutic approach to deal and manage the treatment associated with deadly nCOVID-19 (96).

After the nCOVID-19 disaster, many researchers around the globe combine the stem cell infusion for treating COVID mobility and mortality, one such study was published in China on a stem cell based clinical trial that improved the critical case of 65 years old Chinese women suffering from nCOVID-19 after the infusion of MSCs (97). After this publication published in the scientific market, many clinical stem cell trials have been started since date, another report from Beijing responded positive outcomes on treating seven nCOVID-19 patients with stem cell therapy (28). WHO has also created the central database around the globe running stem cell clinical trials to treat the deadly virus nCOVID-19. Finally, in February 2020, Director of Biological Technology, Ministry of Science and Technology in Beijing, Mr. Zhang Xinmin, during a press conference, announced the safety and effectiveness of stem cell-based therapy based on preliminary experimental results running across the country (98).

\section{Role of hMSCs in coronavirus pandemic}

hMSCs have been used frequency from basic regenerative, translation research to human clinical trials $(28,99,100)$. MSCs safety and effectiveness have already been clearly recognized in numerous clinical trial studies like in Graftversus-host disease (GVHD) (101) or Systematic lupus erythematosus (SLE) (102). After the nCOVID-19 infection, the body tends to accelerate the immune overreaction which further produces a large number of inflammatory factors, thus initiating cytokine storm with an overproduction of immune cells and cytokines (103). Here, comes the role of Corona warrior, i.e., the MSC therapy for treating nCOVID-19 patients. Mesenchymal SCs shows a key and lead role primarily into two different ways, their differentiation abilities and immunomodulatory effects $(27,28,31)$. At a cellular level, Mesenchymal SCs itself contains some natural immunity towards the coronavirus due to their powerful immunomodulatory capability. Mesenchymal SCs have valuable effects in preventing or attenuating the cytokine storm simply by secreting antiinflammatory factors (31) by paracrine secretion (28). Mesenchymal SCs with the ability of paracrine secretion may secrete many types of cytokines or make direct interaction with certain immune cells like T cells, B cells, macrophages, natural killer cells and dendrite cells (31) The Mesenchymal SCs immunomodulatory effect is further triggered by the stimulation of TLR receptor in Mesenchymal SCs, which is stimulated by pathogenassociated molecules such as novel coronavirus double- 
stranded RNA or LPS $(104,105)$. Mesenchymal SC therapy inhibits the overreaction by the immune system and thereby encourage endogenous repair, i.e., reparative trait of SCs by improving the microenvironment $(27,31)$. After intravenous injection of MSCs, some part of Mesenchymal SCs entraps within the lungs, which further improves the pulmonary microenvironment by protecting alveolar epithelial cells, prevent pulmonary fibrosis and improve overall lung dysfunction and nCOVID-19 associated pneumonia $(28,82,83)$. MSCs have also stand-up superior in improving functions related to cardiovascular, hepatic, renal, acute respiratory syndrome and multiple other disorders $(85,106)$.

Therefore, it can be stated that MSCs based therapy may possibly play a key and warrior role for clinical trial in combination with conventional treatment to explore the therapeutic potential to treat nCOVID-19 infected patients (28).

\section{Challenges and future prospects}

MSCs have in many of the clinical and preclinical trials have shown promising results in conditions of inflammatory airway disorders and other immune disorders. This has led the researchers to plan and conduct clinical trials to combat the nCOVID-19 pandemic, as the major symptoms of an attack are related to inflammatory airway disorders. Though we have many questions in mind, the need of the hour is to find out a solution for this pandemic and hence no stone should be left unturned, which may lead us in mitigating the symptoms of the disease. MSCs derived from different tissue sources show many similarities and they also exhibit obvious differences in their properties and this is a very important point which should be kept in consideration.

In one the of the study performed by Yang et al. in 2013 (107), Biological and phenotypic characteristics of different MSCs sources were compared, sources included were adiposeMSCs, bone marrow-MSCs, umbilical cord-MSCs and chorionic villi-MSCs. The results have demonstrated CD106+ (VCAM-1) was highly expressed in chorionic villi-MSCs, fairly on bone marrow-MSCs, and very light expression was observed on umbilical cord-MSCs, however, the expression was absent on adipose-MSCs. The CD106+ cells have shown to be more efficient in the modulation of $\mathrm{T}$ helper subsets (107). Umbilical based MSCs and Wharton Jelly based MSCs are also being used in managing critically ill nCOVID-19 Patients have been suggested by some of the research groups in the UK and China (31,108-110).

These are some hope inducing studies wherein it has been shown that the management of the nCOVID-19 cases is possible with cell-based therapy. However, there are several questions which need to be answered. Many more randomized and multicentric clinical trials will throw more light into this domain. With such clinical trials and exchange of data, we may narrow down the type of stem cells, dose, route of injection and follow-up interventions requirement $(111,112)$.

Apart from these, there are many more questions which need to be answered. As many of the studies are using the cultured MSCs, we need to understand and compare the culture condition of the different laboratories. Which are the signaling pathway modulated by these cells? Where exactly in the signaling pathway cytokines secreted by MSCs act? How theses MSCs infusion will affect an nCOVID-19 patient having comorbidity? How the safety regulations of the previous trials will pave the way for a more safe and effective treatment? (113).

We will be able to make these trials, even more, useful and meaningful, if we try to find out the answer to these questions and many more which we may not have thought. More and more cooperation in research and developments is required to combat this pandemic and the better and free exchange of results, findings need to be shared among the affected countries, to mount a good attack on the virus.

\section{Acknowledgments}

Funding: None.

\section{Footnote}

Reporting Checklist: The authors have completed the narrative review reporting checklist. Available at https:// dx.doi.org/10.21037/sci-2020-040

Conflicts of Interest: All authors have completed the ICMJE uniform disclosure form (available at https://dx.doi. org/10.21037/sci-2020-040). The authors have no conflicts of interest to declare.

Ethical Statement: The authors are accountable for all aspects of the work in ensuring that questions related to the accuracy or integrity of any part of the work are appropriately investigated and resolved.

Open Access Statement: This is an Open Access article distributed in accordance with the Creative Commons Attribution-NonCommercial-NoDerivs 4.0 International 
License (CC BY-NC-ND 4.0), which permits the noncommercial replication and distribution of the article with the strict proviso that no changes or edits are made and the original work is properly cited (including links to both the formal publication through the relevant DOI and the license). See: https://creativecommons.org/licenses/by-nc-nd/4.0/.

\section{References}

1. Caplan AI. The mesengenic process. Clin Plast Surg 1994;21:429-35.

2. Horwitz EM, Le Blanc K, Dominici M, et al. Clarification of the nomenclature for MSC: The International Society for Cellular Therapy position statement. Cytotherapy 2005;7:393-5.

3. Dominici M, Le Blanc K, Mueller I, et al. Minimal criteria for defining multipotent mesenchymal stromal cells. The International Society for Cellular Therapy position statement. Cytotherapy 2006;8:315-7.

4. van Vliet P, Sluijter JP, Doevendans PA, et al. Isolation and expansion of resident cardiac progenitor cells. Expert Rev Cardiovasc Ther 2007;5:33-43.

5. Zvaifler NJ, Marinova-Mutafchieva L, Adams G, et al. Mesenchymal precursor cells in the blood of normal individuals. Arthritis Res 2000;2:477-88.

6. Rogers I, Casper RF. Umbilical cord blood stem cells. Best Pract Res Clin Obstet Gynaecol 2004;18:893-908.

7. Péault B, Rudnicki $M$, Torrente $Y$, et al. Stem and progenitor cells in skeletal muscle development, maintenance, and therapy. Mol Ther 2007;15:867-77.

8. Pittenger MF, Mackay AM, Beck SC, et al. Multilineage potential of adult human mesenchymal stem cells. Science 1999;284:143-7.

9. Griffiths MJ, Bonnet D, Janes SM. Stem cells of the alveolar epithelium. Lancet 2005;366:249-60.

10. Nöth U, Osyczka AM, Tuli R, et al. Multilineage mesenchymal differentiation potential of human trabecular bone-derived cells. J Orthop Res 2002;20:1060-9.

11. Brittan M, Wright NA. Gastrointestinal stem cells. J Pathol 2002;197:492-509.

12. Bussolati B, Bruno $S$, Grange C, et al. Isolation of renal progenitor cells from adult human kidney. Am J Pathol 2005;166:545-55.

13. Herrera $M B$, Bruno $S$, Buttiglieri $S$, et al. Isolation and characterization of a stem cell population from adult human liver. Stem Cells 2006;24:2840-50.

14. Koblas T, Zacharovová K, Berková Z, et al. Isolation and characterization of human CXCR4-positive pan-creatic cells. Folia Biol (Praha) 2007;53:13-22.

15. De Bari C, Dell'Accio F, Luyten FP. Human periosteumderived cells maintain phenotypic stability and chondrogenic potential throughout expansion regardless of donor age. Arthritis Rheum 2001;44:85-95.

16. Levy V, Lindon C, Zheng Y, et al. Epidermal stem cells arise from the hair follicle after wounding. FASEB J 2007;21:1358-66.

17. Lyle S, Christofidou-Solomidou M, Liu Y, et al. Human hair follicle bulge cells are biochemically distinct and possess an epithelial stem cell phenotype. J Investig Dermatol Symp Proc 1999;4:296-301.

18. Mohanty S, Kumar A, Dhawan J, et al. Depletion of CD200+ Hair Follicle Stem Cells in Human Prematurely Gray Hair Follicles. J Cutan Aesthet Surg 2013;6:90-2.

19. Ourednik J, Ourednik V, Lynch WP, et al. Neural stem cells display an inherent mechanism for rescuing dysfunctional neurons. Nat Biotechnol 2002;20:1103-10.

20. Shi $\mathrm{Y}$, Inoue $\mathrm{H}, \mathrm{Wu} \mathrm{JC}$, et al. Induced pluripotent stem cell technology: a decade of progress. Nat Rev Drug Discov 2017;16:115-30.

21. Ullah I, Subbarao RB, Rho GJ. Human mesenchymal stem cells - current trends and future prospective. Biosci Rep 2015;35:00191.

22. Fan XL, Zhang Z, Ma CY, et al. Mesenchymal stem cells for inflammatory airway disorders: promises and challenges. Biosci Rep 2019;39:BSR20182160.

23. Gao F, Chiu SM, Motan DA, et al. Mesenchymal stem cells and immunomodulation: current status and future prospects. Cell Death Dis 2016;7:e2062.

24. Park MJ, Kwok SK, Lee SH, et al. Adipose tissuederived mesenchymal stem cells induce expansion of interleukin-10-producing regulatory B cells and ameliorate autoimmunity in a murine model of systemic lupus erythematosus. Cell Transplant 2015;24:2367-77.

25. Guo Y, Chan KH, Lai WH, et al. Human mesenchymal stem cells upregulate $\mathrm{CD} 1 \mathrm{dCD} 5(+)$ regulatory $\mathrm{B}$ cells in experimental autoimmune encephalomyelitis. Neuroimmunomodulation 2013;20:294-303.

26. Liu S, Peng D, Qiu H, et al. Mesenchymal stem cells as a potential therapy for COVID-19. Stem Cell Res Ther 2020;11:169.

27. Golchin A, Seyedjafari E, Ardeshirylajimi A. Mesenchymal Stem Cell Therapy for COVID-19: Present or Future. Stem Cell Rev Rep 2020;16:427-33.

28. Leng Z, Zhu R, Hou W, et al. Transplantation of ACE2Mesenchymal Stem Cells Improves the Outcome of Patients with COVID-19 Pneumonia. Aging Dis 
2020;11:216-28.

29. Rajarshi K, Chatterjee A, Ray S. Combating COVID-19 with mesenchymal stem cell therapy. Biotechnol Rep (Amst) 2020;26:e00467.

30. Moll G, Drzeniek N, Kamhieh-Milz J, et al. MSC Therapies for COVID-19: Importance of Patient Coagulopathy, Thromboprophylaxis, Cell Product Quality and Mode of Delivery for Treatment Safety and Efficacy. Front Immunol 2020;11:1091.

31. Atluri S, Manchikanti L, Hirsch JA. Expanded Umbilical Cord Mesenchymal Stem Cells (UC-MSCs) as a Therapeutic Strategy in Managing Critically Ill COVID-19 Patients: The Case for Compassionate Use. Pain Physician 2020;23:E71-83.

32. Su S, Wong G, Shi W, et al. Epidemiology, Genetic Recombination, and Pathogenesis of Coronaviruses. Trends Microbiol 2016;24:490-502.

33. Zhou P, Yang XL, Wang XG, et al. A pneumonia outbreak associated with a new coronavirus of probable bat origin. Nature 2020;579:270-3.

34. Perlman S, Netland J. Coronaviruses post-SARS: update on replication and pathogenesis. Nat Rev Microbiol 2009;7:439-50.

35. Li X, Geng M, Peng Y, et al. Molecular immune pathogenesis and diagnosis of COVID-19. J Pharm Anal 2020;10:102-8.

36. Masters PS. The molecular biology of coronaviruses. Adv Virus Res 2006;66:193-292.

37. Huang C, Wang Y, Li X, et al. Clinical features of patients infected with 2019 novel coronavirus in Wuhan, China. Lancet 2020;395:497-506.

38. Peiris JS, Guan Y, Yuen KY. Severe acute respiratory syndrome. Nat Med 2004;10:S88-97.

39. de Wit E, van Doremalen N, Falzarano D, et al. SARS and MERS: recent insights into emerging coronaviruses. Nat Rev Microbiol 2016;14:523-34.

40. Xu X, Chen P, Wang J, et al. Evolution of the novel coronavirus from the ongoing Wuhan outbreak and modeling of its spike protein for risk of human transmission. Sci China Life Sci 2020;63:457-60.

41. Lu R, Zhao X, Li J, et al. Genomic characterisation and epidemiology of 2019 novel coronavirus: implications for virus origins and receptor binding. Lancet 2020;395:565-74.

42. Wu F, Zhao S, Yu B, et al. A new coronavirus associated with human respiratory disease in China. Nature 2020;579:265-9.

43. Li W, Moore MJ, Vasilieva N, et al. Angiotensin- converting enzyme 2 is a functional receptor for the SARS coronavirus. Nature 2003;426:450-4.

44. Jeffers SA, Tusell SM, Gillim-Ross L, et al. CD209L (L-SIGN) is a receptor for severe acute respiratory syndrome coronavirus. Proc Natl Acad Sci U S A 2004;101:15748-53.

45. Raj VS, Mou H, Smits SL, et al. Dipeptidyl peptidase 4 is a functional receptor for the emerging human coronavirusEMC. Nature 2013;495:251-4.

46. Hamming I, Timens W, Bulthuis ML, et al. Tissue distribution of ACE2 protein, the functional receptor for SARS coronavirus. A first step in understanding SARS pathogenesis. J Pathol 2004;203:631-7.

47. Riccioni L, Bertolini G, Giannini A, et al. Raccomandazioni Di Etica Clinica Per L'AmmissioneA Trattamenti Intensivi E Per La Loro Sospensione, In Condizioni Eccezionali Di Squilibrio Tra Necessità E RisORSE Disponibili. Recenti Prog Med 2020;111:207-11.

48. Hoffmann M, Kleine-Weber H, Krüger N, et al. The novel coronavirus 2019 (2019-nCoV) uses the SARScoronavirus receptor ACE2 and the cellularprotease TMPRSS2 for entry into target cells. bioRxiv 2020. doi: https://doi.org/10.1101/2020.01.31.929042.

49. Glowacka I, Bertram S, Müller MA, et al. Evidence that TMPRSS2 activates the severe acute respiratory syndrome coronavirus spike protein for membrane fusion and reduces viral control by the humoral immune response. $\mathrm{J}$ Virol 2011;85:4122-34.

50. Iwata-Yoshikawa N, Okamura T, Shimizu Y, et al. TMPRSS2 Contributes to Virus Spread and Immunopathology in the Airways of Murine Models after Coronavirus Infection. J Virol 2019;93:e01815-18.

51. Simmons G, Reeves JD, Rennekamp AJ, et al. Characterization of severe acute respiratory syn-dromeassociated coronavirus (SARS-CoV) spike glycoproteinmediated viral entry. Proc Natl Acad Sci U S A 2004;101:4240-5.

52. Belouzard S, Chu VC, Whittaker GR. Activation of the SARS coronavirus spike protein via sequential pro-teolytic cleavage at two distinct sites. Proc Natl Acad Sci U S A 2009;106:5871-6.

53. Wang H, Yang P, Liu K, et al. SARS coronavirus entry into host cells through a novel clathrin- and caveo-laeindependent endocytic pathway. Cell Res 2008;18:290-301.

54. Kuba K, Imai Y, Ohto-Nakanishi T, et al. Trilogy of ACE2: a peptidase in the renin-angiotensin system, a SARS receptor, and a partner for amino acid transporters. Pharmacol Ther 2010;128:119-28. 
55. Liu J, Wu P, Gao F, et al. Novel immunodominant peptide presentation strategy: a featured HLA-A*2402-restricted cytotoxic T-lymphocyte epitope stabilized by intrachain hydrogen bonds from severe acute respiratory syndrome coronavirus nucleocapsid protein. J Virol 2010;84:11849-57.

56. Keicho N, Itoyama S, Kashiwase K, et al. Association of human leukocyte antigen class II alleles with severe acute respiratory syndrome in the Vietnamese population. Hum Immunol 2009;70:527-31.

57. Chen YM, Liang SY, Shih YP, et al. Epidemiological and genetic correlates of severe acute respiratory syn-drome coronavirus infection in the hospital with the highest nosocomial infection rate in Taiwan in 2003. J Clin Microbiol 2006;44:359-65.

58. Wang SF, Chen KH, Chen M, et al. Human-leukocyte antigen class I Cw 1502 and class II DR 0301 genotypes are associated with resistance to severe acute respiratory syndrome (SARS) infection. Viral Immunol 2011;24:421-6.

59. Hajeer AH, Balkhy H, Johani S, et al. Association of human leukocyte antigen class II alleles with severe Middle East respiratory syndrome-coronavirus infection. Ann Thorac Med 2016;11:211-3.

60. Tu X, Chong WP, Zhai Y, et al. Functional polymorphisms of the CCL2 and MBL genes cumulatively increase susceptibility to severe acute respiratory syndrome coronavirus infection. J Infect 2015;71:101-9.

61. Snijder EJ, van der Meer Y, Zevenhoven-Dobbe J, et al. Ultrastructure and origin of membrane vesicles as-sociated with the severe acute respiratory syndrome coronavirus replication complex. J Virol 2006;80:5927-40.

62. Channappanavar R, Fehr AR, Vijay R, et al. Dysregulated Type I Interferon and Inflammatory Mono-cyteMacrophage Responses Cause Lethal Pneumonia in SARSCoV-Infected Mice. Cell Host Microbe 2016;19:181-93.

63. Channappanavar R, Fehr AR, Zheng J, et al. IFN-I response timing relative to virus replication determines MERS coronavirus infection outcomes. J Clin Invest 2019;129:3625-39.

64. Niemeyer D, Zillinger T, Muth D, et al. Middle East respiratory syndrome coronavirus accessory protein $4 \mathrm{a}$ is a type I interferon antagonist. J Virol 2013;87:12489-95.

65. Yang $\mathrm{Y}$, Zhang L, Geng $\mathrm{H}$, et al. The structural and accessory proteins $M$, ORF 4a, ORF 4b, and ORF 5 of Middle East respiratory syndrome coronavirus (MERS$\mathrm{CoV}$ ) are potent interferon antagonists. Protein Cell 2013;4:951-61.

66. Menachery VD, Schäfer A, Burnum-Johnson KE, et al. MERS-CoV and $\mathrm{H} 5 \mathrm{~N} 1$ influenza virus antagonize antigen presentation by altering the epigenetic landscape. Proc Natl Acad Sci U S A 2018;115:E1012-21.

67. Williams AE, Chambers RC. The mercurial nature of neutrophils: still an enigma in ARDS? Am J Physiol Lung Cell Mol Physiol 2014;306:L217-30.

68. Channappanavar R, Perlman S. Pathogenic human coronavirus infections: causes and consequences of cytokine storm and immunopathology. Semin Immunopathol 2017;39:529-39.

69. Cameron MJ, Bermejo-Martin JF, Danesh A, et al. Human immunopathogenesis of severe acute respiratory syndrome (SARS). Virus Res 2008;133:13-9.

70. Min CK, Cheon S, Ha NY, et al. Comparative and kinetic analysis of viral shedding and immunological re-sponses in MERS patients representing a broad spectrum of disease severity. Sci Rep 2016;6:25359.

71. Li G, Chen X, Xu A. Profile of specific antibodies to the SARS-associated coronavirus. N Engl J Med 2003;349:508-9.

72. Xu Z, Shi L, Wang Y, et al. Pathological findings of COVID-19 associated with acute respiratory distress syndrome. Lancet Respir Med 2020;8:420-2.

73. Fan YY, Huang ZT, Li L, et al. Characterization of SARS$\mathrm{CoV}$-specific memory $\mathrm{T}$ cells from recovered in-dividuals 4 years after infection. Arch Virol 2009;154:1093-9.

74. Tang F, Quan Y, Xin ZT, et al. Lack of peripheral memory $B$ cell responses in recovered patients with severe acute respiratory syndrome: a six-year follow-up study. J Immunol 2011;186:7264-8.

75. Zhao J, Li K, Wohlford-Lenane C, et al. Rapid generation of a mouse model for Middle East respiratory syndrome. Proc Natl Acad Sci U S A 2014;111:4970-5.

76. Callaway E. The race for coronavirus vaccines: a graphical guide. Nature 2020;580:576-7.

77. MedicalXpress Breaking News and Events. Coronavirus drugs: Who's doing what, and when they might come. Available online: https://medicalxpress.com/news/202003-coronavirus-drugs.html, 2020, accessed 14 June, 2020.

78. Liang P, Ye F, Hou CC, et al. Mesenchymal stem cell therapy for patients with ischemic heart failurepast, present, and future. Curr Stem Cell Res Ther 2021;16:608-21.

79. Bartolucci J, Verdugo FJ, González PL, et al. Safety and Efficacy of the Intravenous Infusion of Umbilical Cord Mesenchymal Stem Cells in Patients With Heart Failure: A Phase 1/2 Randomized Controlled Trial (RIMECARD Trial Randomized Clinical Trial of Intravenous Infusion Umbilical Cord Mesenchymal Stem Cells on Cardiopathy). 
Circ Res 2017;121:1192-204.

80. Shafei AE, Ali MA, Ghanem HG, et al. Mesenchymal stem cell therapy: A promising cell-based therapy for treatment of myocardial infarction. J Gene Med 2017;19:10.1002/ jgm.2995.

81. Behnke J, Kremer S, Shahzad T, et al. MSC Based Therapies-New Perspectives for the Injured Lung. J Clin Med 2020;9:682.

82. Cruz FF, Rocco PRM. The potential of mesenchymal stem cell therapy for chronic lung disease. Expert Rev Respir Med 2020;14:31-9.

83. Li D, Liu Q, Qi L, et al. Low levels of TGF- $\beta 1$ enhance human umbilical cord-derived mesenchymal stem cell fibronectin production and extend survival time in a rat model of lipopolysaccharide-induced acute lung injury. Mol Med Rep 2016;14:1681-92.

84. Iyer SS, Co C, Rojas M. Mesenchymal stem cells and inflammatory lung diseases. Panminerva Med 2009;51:5-16.

85. Missoum A. Recent Updates on Mesenchymal Stem Cell Based Therapy for Acute Renal Failure. Curr Urol 2020;13:189-99.

86. Qian X, Xu C, Fang S, et al. Exosomal MicroRNAs Derived From Umbilical Mesenchymal Stem Cells Inhibit Hepatitis C Virus Infection. Stem Cells Transl Med 2016;5:1190-203.

87. Gao L, Zhong X, Jin J, et al. Potential targeted therapy and diagnosis based on novel insight into growth factors, receptors, and downstream effectors in acute kidney injury and acute kidney injury-chronic kidney disease progression. Signal Transduct Target Ther 2020;5:9.

88. Federal Trade Commission. FTC stops deceptive health claims by a stem cell therapy clinic. Available online: https://www.ftc.gov/news-events/press-releases/2018/10/ ftc-stops-deceptive-health-claims-stem-cell-therapy-clinic, 2018, accessed 15 June, 2020.

89. Daley GQ. Polar Extremes in the Clinical Use of Stem Cells. N Engl J Med 2017;376:1075-7.

90. FDA News Release. FDA acts to remove unproven, potentially harmful treatment used in 'stem cell' centers targeting vulnerable patients. Vaccinia Virus Vaccine (Live) seized after being used inappropriately in vulnerable cancer patients. Available online: https://www.fda.gov/newsevents/press-announcements/fda-acts-remove-unprovenpotentially-harmful-treatment-used-stem-cell-centerstargeting-vulnerable, 2017, accessed 15 June, 2020.

91. Regulatory Considerations for Human Cell, Tissues, and Cellular and Tissue-Based Products: Minimal Manipulation and Homologous Use. Guidance for
Industry and Food and Drug Administration Staff, November 2017. Available online: https://www.fda.gov/ regulatory-information/search-fda-guidance-documents/ regulatory-considerations-human-cells-tissues-andcellular-and-tissue-based-products-minimal, 2017. Accessed 15 June, 2020.

92. U.S. Department of Health and Human Services, Same Surgical Procedure Exception under 21 CFR 1271.15(b): Questions and Answers Regarding the Scope of the Exception. Guidance for Industry. Available online: https://www.fda.gov/regulatory-information/search-fdaguidance-documents/same-surgical-procedure-exceptionunder-21-cfr-127115b-questions-and-answers-regardingscope, 2017, accessed 14 June, 2020.

93. Schwarz A. New procedure uses athletes' own blood to treat injuries. New York Times. Available online: https:// www.nytimes.com/2009/02/17/sports/17blood.html, 2009. Accessed 20 June, 2020.

94. Piuzzi NS, $\operatorname{Ng}$ M, Chughtai M, et al. The Stem-Cell Market for the Treatment of Knee Osteoarthritis: A Patient Perspective. J Knee Surg 2018;31:551-6.

95. Turner L, Knoepfler P. Selling Stem Cells in the USA: Assessing the Direct-to-Consumer Industry. Cell Stem Cell 2016;19:154-7.

96. Metcalfe SM. Mesenchymal stem cells and management of COVID-19 pneumonia. Med Drug Discov 2020;5:100019.

97. Liang B, Chen J, Li T, et al. Clinical remission of a critically ill COVID-19 patient treated by human umbilical cord mesenchymal stem cells: A case report. Medicine (Baltimore) 2020;99:e21429.

98. Knoepfler P. 'We Cannot Stick to the Rules': claims of stem cells saving COVID-19 patients. The Niche. Available online: https://ipscell.com/2020/03/we-cannotstick-to-the-rules-claims-of-stem-cells-saving-covid-19patients, 2020, accessed 14 June, 2020.

99. Connick P, Kolappan M, Crawley C, et al. Autologous mesenchymal stem cells for the treatment of sec-ondary progressive multiple sclerosis: an open-label phase $2 \mathrm{a}$ proof-of-concept study. Lancet Neurol 2012;11:150-6.

100. Wilson JG, Liu KD, Zhuo H, et al. Mesenchymal stem (stromal) cells for treatment of ARDS: a phase 1 clinical trial. Lancet Respir Med 2015;3:24-32.

101.Hashmi S, Ahmed M, Murad MH, et al. Survival after mesenchymal stromal cell therapy in ster-oid-refractory acute graft-versus-host disease: systematic review and meta-analysis. Lancet Haematol 2016;3:e45-52.

102. Kamen DL, Nietert PJ, Wang H, et al. CT-04 Safety and efficacy of allogeneic umbilical cord-derived mesenchymal 
stem cells (MSCs) in patients with systemic lupus erythematosus: results of an open-label phase I study.

Lupus Science \& Medicine 2018;5:46-47.

103. Mehta P, McAuley DF, Brown M, et al. COVID-19: consider cytokine storm syndromes and immunosuppression. Lancet 2020;395:1033-4.

104. Waterman RS, Tomchuck SL, Henkle SL, et al. A new mesenchymal stem cell (MSC) paradigm: polar-ization into a pro-inflammatory MSC1 or an Immunosuppressive MSC2 phenotype. PLoS One 2010;5:e10088.

105.Li W, Ren G, Huang Y, et al. Mesenchymal stem cells: a double-edged sword in regulating immune re-sponses. Cell Death Differ 2012;19:1505-13.

106. Abraham A, Krasnodembskaya A. Mesenchymal stem cellderived extracellular vesicles for the treatment of acute respiratory distress syndrome. Stem Cells Transl Med 2020;9:28-38.

107. Yang ZX, Han ZB, Ji YR, et al. CD106 identifies a subpopulation of mesenchymal stem cells with unique immunomodulatory properties. PLoS One 2013;8:e59354.

108. Rogers CJ, Harman RJ, Bunnell BA, et al. Rationale for the clinical use of adipose-derived mesenchymal stem cells

doi: $10.21037 /$ sci-2020-040

Cite this article as: Sachdeva K, Kumar A, Mohanty S. Virology of SARS-CoV-2 and management of nCOVID-19 utilizing immunomodulation properties of human mesenchymal stem cells—a literature review. Stem Cell Investig 2021;8:23. for COVID-19 patients. J Transl Med 2020;18:203.

109. Gorman E, Shankar-Hari M, Hopkins P, et al. Repair of Acute Respiratory Distress Syndrome by Stromal Cell Administration in COVID-19 (REALIST-COVID-19): A structured summary of a study protocol for a randomised, controlled trial. Trials 2020;21:462.

110.Zhang Y, Ding J, Ren S, et al. Intravenous infusion of human umbilical cord Wharton's jelly-derived mesenchymal stem cells as a potential treatment for patients with COVID-19 pneumonia. Stem Cell Res Ther 2020;11:207.

111.Escacena N, Quesada-Hernández E, Capilla-Gonzalez $\mathrm{V}$, et al. Bottlenecks in the Efficient Use of Ad-vanced Therapy Medicinal Products Based on Mesenchymal Stromal Cells. Stem Cells Int 2015;2015:895714.

112. Cagliani J, Grande D, Molmenti EP, et al. Immunomodulation by Mesenchymal Stromal Cells and Their Clinical Applications. J Stem Cell Regen Biol 2017. doi: 10.15436/2471-0598.17.022.

113.Kode JA, Mukherjee S, Joglekar MV, et al. Mesenchymal stem cells: immunobiology and role in im-munomodulation and tissue regeneration. Cytotherapy 2009;11:377-91. 


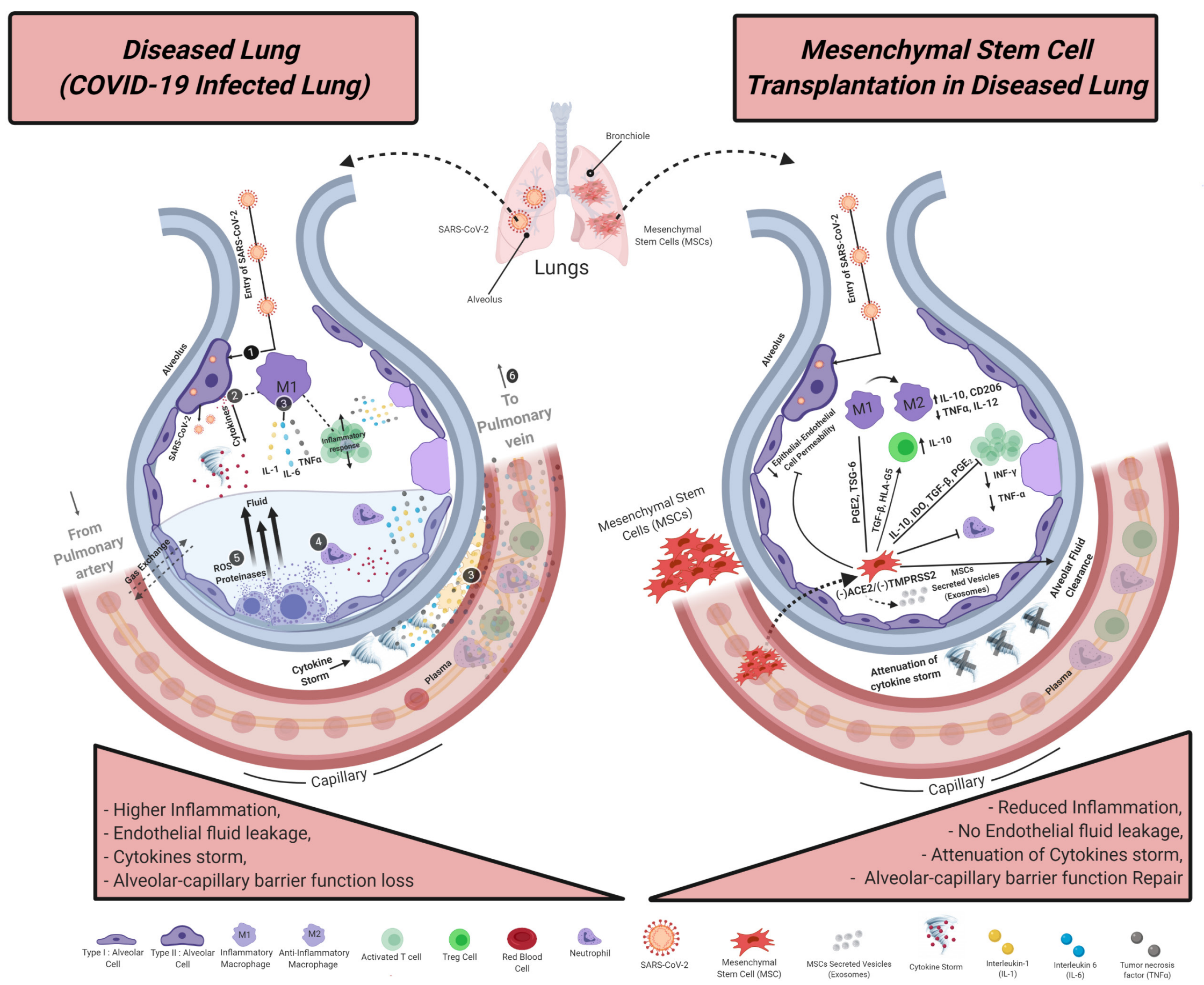

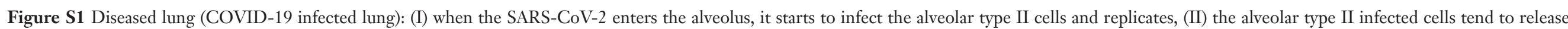

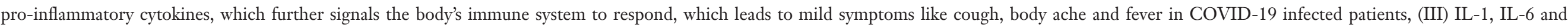

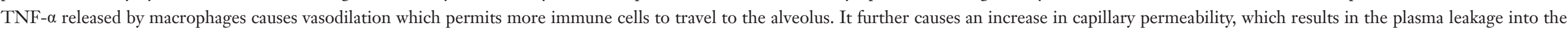

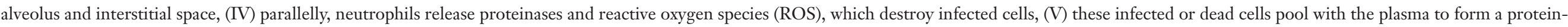

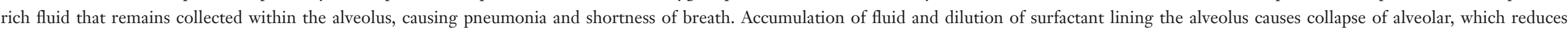

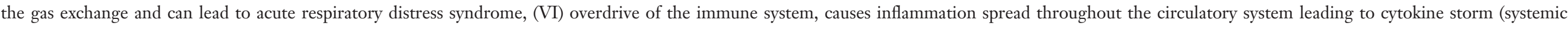

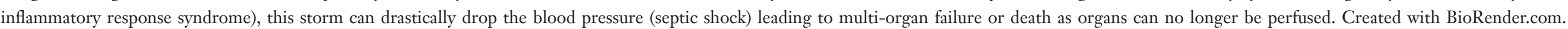

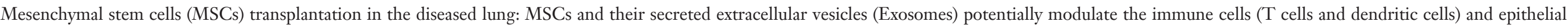

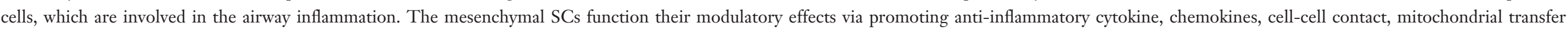

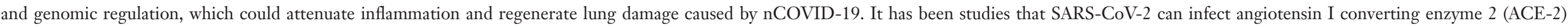

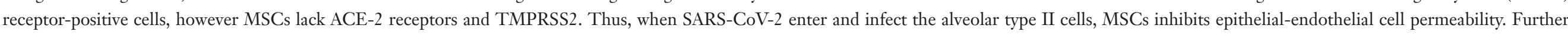

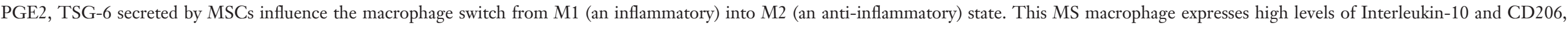

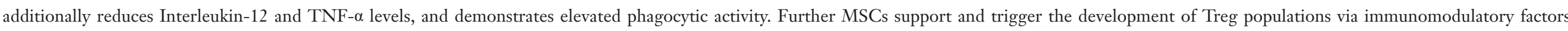

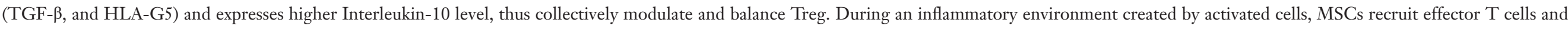

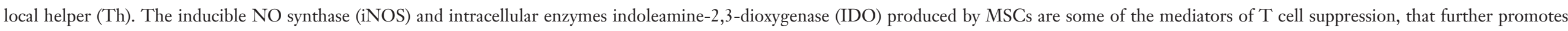

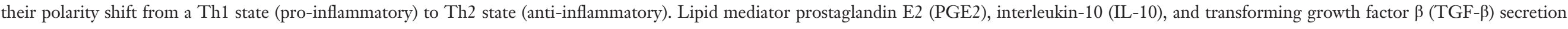

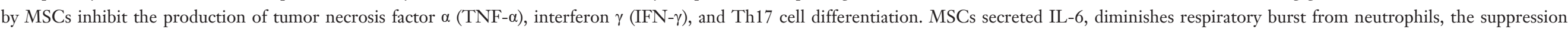

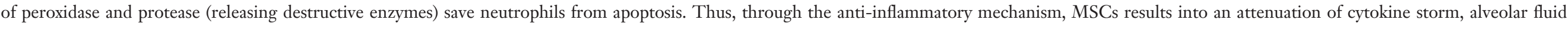
clearance and maintain alveolar-capillary barrier function. Created with BioRender.com. 